Munk, who simply copied it word for word from Watt's "Bibliotheca Britannica" of 1824. P. 58: Redi 1671. There is evidently some confusion here. The work by Redi is not correctly quoted or described, nor was it translated by Waller. P. 122: "Jan Jocoboz [Jacobsz.] Swammerdam" was Swammerdam's father. P. 137: Tyson's Faithorne was the father (1616-1691), not the son. Pp. 152-3 : The tapeworm described by Tyson was Taenia pisiformis of the dog, of which he examined the external characters only; and, even so, unaccountably failed to observe the suckers of the scolex! He does not give us a minute and perfect description of the anatomy of the worm. The worm figured on p. 153 is obviously not a Bothriocephalid but a Taeniidprobably Taenia saginata. P. 161 : Rana piscatrix is not a frog, but the fish Lophius piscatorius. P. 169 : Tyson cannot be acquitted of the belief that the peccary had three stomachs. His language is unmistakable, and he even compares the three stomachs of the peccary with the single stomach of the common pig. Pp. 184 and 388 : Tyson did not discover the cochineal fly. His figures represent one of the Coccinellid predators of that insect. P. 196 : Hartmann recognized the animal nature of hydatids in 1685 before Tyson. P. 211 and also kibliography and index: Powers is the possessive case of Power. P. 283 : The progressive diminution of the thymus during life was known to Galen. P. 327 : Neither Tyson nor Hale discovered the human allantois, judging from Hale's paper. P. 357 : Tyson's "yellow gurnard" was Callionymus lyra. P. 382 : Perrault's philosophical views on comparative anatomy do not appear in the Parisian memoirs, but in his "Essais de Physique", and they compare very favourably with those expressed in Tyson's "Preliminary Discourse". P. 390 : Grew (1675 and again in 1681) was the first to use the expression comparative anatomy in the title-page of a book. P. 408: In the Opera Omnia of Tyson, published in 1751, the unsold copies of the first and only edition of the anatomy of the Pygmie of 1699 were bound up with reprints of Tyson's other works. A comparison of the two "editions" of the Pygmie work shows that they are absolutely identical in every respect, and the relative scarcity of the 1751 edition is due to the small number of copies of the Pygmie which were available for this issue.

F. J. Cole.

\section{ADVANCES IN BIOCHEMISTRY}

\section{Annual Review of Biochemistry}

James Murray Luck, Editor; James H. C. Smith, Associate Editor. Vol. 12. Pp. ix + 704. (Stanford University P.O., Calif.: Annual Review, Inc., 1943.) 5 dollars.

Trot HIS, the twelfth volume of the "Annual Review of Biochemistry", is a remarkable production in that it shows so little evidence of war and all that war is meaning to the scientific worker. We need not recapitulate the difficulties which face the research worker; easy exchange of information and of publications is a thing of the past, and the censorship and import regulations have added greatly to the difficulty of our getting much-needed scientific books from the United States. In those many sections of scientific activity which make up biochemistry, the "Review" is more than ever useful in keoping us in touch.
The volume contains the usual articles on progress in what may be termed standard sections of the subject, but we would direct attention more particu. larly to the sections in the latter half of the volume as examples of its utility. Experimental progress waits largely on an advance in technique such as is afforded by the recent development of microchemical methods: it is affirmed that chemical behaviour remains essentially unchanged when only $10^{-8}-10^{-10}$ gm. of matter is used. The section describing the developments in these methods is most helpful.

There is a report for the first time on the electron microscope, which has progressed rapidly since the building of the first compound instruments ten years ago.

In the study of the biochemistry of micro-organ. isms there has been a striking shift in emphasis, changing to the study of microbial nutrition from that of metabolism. Many growth-factors have been identified with typical vitamins, so that the results have a direct bearing on the nutrition of higher organisms. The report includes a summary of work on anti-bacterial agents such as the sulphonamides and penicillin. Synthesis of vitamins by culture of Torula yeast on wood-sugar and other industrial wastes has been known for some time, and such work is being extended.

The demonstration that plant viruses are protein macro-molecules brought the chemist and the physicist into this field. The review describes the formation of acetyl and phenyl-ureido derivatives of tobacco mosaic virus and their inoculation into susceptible hosts. The experiments are thought to show that infecting virus molecules may not necessarily function as exact patterns for reproduction, while a large proportion of certain functional groups of the virus molècule may be changed without appreciably alter. ing the virus activity. There is much work on tobacco mosaic virus, including the determination of its constituent amino-acids.

No subject is more to the fore to-day than nutrition, and there is a stimulating report on it. In Great Britain much is being done to persuade a conservative and ignorant public to eat the proper things, and there is a marked change for the better in general health in consequence. The value of an improved diet during pregnancy on the course of pregnancy, labour and convalescence of the mother and on the general well-being of the baby is firmly established, and action has been taken to make it available here. For the masses the lack of oranges and other fresh fruits is a serious disability; the vitamins lost are only very partially made up from vegetables, which are very hard to obtain fresh in the cities, where they are most needed. Vegetables also are far too dear, almost beyond the purse of many, and it is a reflection on the Ministry of Food that while recommending us to eat more vegetables we are not safeguarded against extortion.

Space restricts any more detailed reference to the other sections, though we may mention the steady but slow progress in the study of the proteins. This is difficult and somewhat unfashionable work, but we are behind in our knowledge. In discussing the sugars, emphasis has been placed upon the effect of unsaturation in directing and influencing not merely carbohydrate reactions but also biological reactions in general.

The editors and their helpers are to be congratulated on a most useful piece of work.

E. F. ARmstrong. 